\title{
Mechanical and Barrier Properties of PE, PP, Surlyn and EVA/Clay Nanocomposites for packaging films
}

\author{
A.Tesarikova ${ }^{\mathrm{a}}$, D. Merinska ${ }^{* a, b}$ \\ ${ }^{\mathrm{a}}$ Department of Polymer Engineering, \\ Faculty of Technology, Tomas \\ Bata University in Zlin, Nam. T. G. Masaryka 275, 76272 Zlin, \\ CZECH REPUBLIC \\ ${ }^{\mathrm{b}}$ Centre of Polymer Systems, \\ University Institute, Tomas Bata \\ University in Zlin, Nad Ovcirnou 3685, 76001 Zlin, \\ CZECH REPUBLIC
}

\begin{abstract}
The article deals with the preparation, properties and the usage of polymer barrier films. The problem of exfoliation and dispersion of the filler in the polymer matrix and mechanical properties of barrier films is discussed. This problem is connected with the use of nanofiller either in the polymer matrix or on the surface of prepared films. Together the evaluating comparison of used nanofillers is done. Polypropylene, polyethylene, EVA copolymer and Surlyn were used like polymer matrices. Organically modified montmorillonite (Cloisite 93A, 30B, 10A, Dellite 67, Nanofil 5) and MMT Na + were used like nanofillers. Next to the clays microprecipitated $\mathrm{CaHCO} 3$, nanosilica and Halloysite tubes were used. The quantity of all the above-mentioned (nano)fillers was 1,3 and $5 \mathrm{wt} . \%$ in relation to the content of montmorillonite. The aim was to evaluate the influence of (nano)filler type and concentration on nanocomposite barrier properties.
\end{abstract}

Morphology (TEM, XRD) and mechanical properties were observed. Furthermore, permeability for O2 and CO2 were evaluated.

Keywords: (nano)composites, clay, montmorillonite, polyolefins, nanofillers, polymers, mechanical and barrier properties,

\section{INTRODUCTION}

Polyolefins is a group of polymers with a very low polarity character. Due to this fact, the mixing them with organic fillers is very difficult. It is very problematic to achieve a good compatibility of a polymer matrix with filler particle surface and by this to obtain required improvement of properties. This holds true for preparation of polymer nanocomposites ${ }^{1-5}$. Generally, polyolefins are not willing to form intercalated or even exfoliated nanocomposites in the presence of a layered silicate clay as smoothly as polar polymers such as poly(amide)s $\mathrm{s}^{5,6}$. This problem can be solved or by using "compatibilizers" (maleated PP or PE) or by polar side-chains grafted to the polyolefin backbone have been utilized to aid in the intercalation and exfoliation of layered clays ${ }^{7,8}$. Nowadays also EVA polymer is used - the number of works based on the study of EVA copolymer and even EVA nanocomposites has become wider and wider ${ }^{10-12}$. Nanofiller combined with PE, PP or EVA copolymer matrix not only improve the gas barrier properties, but also increase a wide range of other useful properties, such as tensile strength and modulus, flammability resistance etc ${ }^{13-15}$. Another big advantage is the possibility of easier recyclation in comparison with the common types of fillers.

Nanocomposites, as it is well known, are prepared by mixing polymer matrix with nanofiller. Generally, they represent layered silicate minerals - clays, where the thickness of the individual leaves is in nanometer size. The most frequently used type of nanoclay is montmorillonite (MMT) ${ }^{16-19}$. It is a layered mineral belonging to a group of clay minerals with octahedral and tetrahedral nets in the ratio of 2:1. In order to increase its exfoliation in the polymeric matrix, it is modified by the process known as organofilization or intercalation, i.e. the insertion of a suitable organic compound into MMT interlayer $^{20-24}$. This way, a broadening $\mathrm{d}$-spacing as well as reduction of gravitational forces between the individual platelets of montmorillonite are reached. Consequently, this leads to the reduction of energy needed for the breakup of nanofiller into the individual nanoleaves in the polymeric matrix after the process of compounding ${ }^{25}$. The function of MMT nanoleaves in the polymer matrix can be observed from two points of view. Generally, the first one is the original effect of filler - the improvement of mechanical properties by increasing the filler surface. The effect of nanofillers rests on 
the ability to create this effect by much lower loading in comparison with common fillers. Another quality of nanoleaves is their positive impact on the orientation of long thick platelets in polymer matrix after compounding, where they are arranged in such a way that they create a gas barrier to the gas transmission. So, the gas permeability is lower. The principle of this phenomenon is shown in the Figure 1.

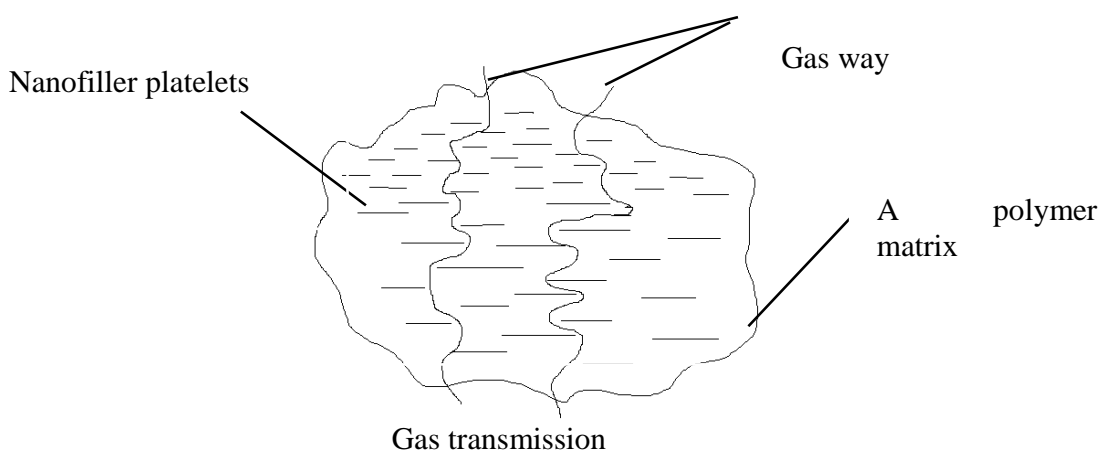

FIG. 1. The principle of gas transmission on polymer nanocomposite matrix

This article was focused on the preparation of PE, PP, EVA copolymer and Surlyn clay nanocomposites with two different ontorillonite concentrations in order to evaluate the influence of various type and loading on prepared nanocomposite properties, such as morphology, mechanical properties and gas barrier properties.

\section{EXPERIMENTAL}

The polymer matrix used as carrier materials were Polyethylene (Borealis RB 707 CF fy Borealis AG) and Polyethylen (Bralen RB 03-23, fy Slovnaft Petrochemicalis Bratislava), EVA (Ultra FL 00218) and Surlyn A (8940). To increase compatibility between the polymer matrix and the filler was used for maleinized PP polypropylene (PP - MA) Exxelor PO 1015 K 1,909,201 13 EXXON and PE maleinized polyethylene (PE - Ma) AMPLIFY GR 216.

\section{Nanofillers}

Were used organically modified montmorillonites with tradenames Cloisite 93A, 30B, 10A (fa Southern Clay Products, Inc.), and Dellite 67G (fa Laviosa Chimica Mineraria S. p A.).

Cloisite ${ }^{\circledR} \mathrm{Na}^{+}$(nontrerated MMT), Nanofiller N5 and N3000 Nanofils from Sudchemie Germany and microprecipitated $\mathrm{CaHCO}_{3}$, nanosilica and Halloysite tubes were used for filling all matrices. The quantity of all the above-mentioned nanofillers added to the polymeric matrix was 1,3 and 5 wt. \% in relation to the content of MMT.

\section{Mixture blending}

Polymers with the fillers (mass fraction $5 \%$ ) were compounded in a twin screw extruder ZE Berstdorff 25, screw diameter was $2 \times 28 \mathrm{~mm}$ and a L / D ratio of 38 The temperature of the individual heating zones and the extrusion head was set at $210^{\circ} \mathrm{C}$ for PP and PE, $160^{\circ} \mathrm{C}$ for EVA and $200^{\circ} \mathrm{C}$ for the Surlyn A rotation speed was 15 per minute. The extruded wire was cooled in a water bath and then transferred using a knife mill back to granulate the unit Scherr SGS - 50E.

\section{Film pressing and blowing}

The next task of our experiment was to extrude films of the thickness of $0.05 \mathrm{~mm}$ for the measurement of barrier properties. The films were extruded on a pre-arranged assembly line consisting of the following parts: an extrusive screw Brabender machine, a special extrusive wide-slot dye, a cooling cylinder and a reel. The thickness of the film was regulated by the speed of the pullout on the one hand and cooling of the cylinder by an electric pump on the other.

On the laboratory blow line TVR - C9S - 7EX (UTB) connected to the extruder single screw unit Brabender OHG Duisburg were prepared from granules blown film. From the prepared granules were pressed plates of dimension $125 \mathrm{x}$ $125 \times 2 \mathrm{~mm}$. The temperature for molding the PP and PE was $210^{\circ} \mathrm{C}, 150^{\circ} \mathrm{C}$ for EVA and for Surlyn $220^{\circ} \mathrm{C}$. The pressing time was 3 minutes for all the polymers and the cooling period was from 7 to 15 minutes. To prepare the solution for deposition of the filler onto the surface of the polymer matrix was used a solvent consisting of ethyl acetate and ethanol, which is a normal part of the polymer printing inks used for printing on transparencies. $150 \mathrm{~g}$ of solvent was added $10 \mathrm{wt} \%$ (15 g), polyvinyl butyral (PVB) and $5 \mathrm{wt} \%(7.5 \mathrm{~g})$ nanofiller. The solution was prepared separately for nanofiller Cloisite 93A and for Dellite 67. 


\section{Evaluation of the samples prepared}

The structure was studied by using an URD-6 Diffractometer in the reflection mode in the range from 0.8000 to $11.9870{ }^{\circ}$ $2 \theta$ at a voltage of $40 \mathrm{kV}$ and $30 \mathrm{~mA}$ with a step size of $0.0263^{\circ}$. The dispersion of the clays in polymer matrix and nanostructures were observed through microscopic investigations.

Samples of $40 \times 20 \mathrm{~mm}$ made from molded plates were sent to the IMC Prague, where it was performed TEM. As samples were used ultrathin sections prepared on special Ultra - cryomikrotom LEICA at $-100{ }^{\circ} \mathrm{C}$, temperature of the knife $-50^{\circ} \mathrm{C}$ and a thickness of about $50 \mathrm{~nm}$. Transmission electron microscopy was performed on a JEM $200 \mathrm{CX}$ at an accelerated voltage of $100 \mathrm{kV}$.

\section{Mechanical properties}

Tensile tests were measured at the Faculty of Technology in UTB Demo Room ALPHA Technologies Ltd. On tensile testing machine TENSOMETR 2000. EN ISO 527-3 (64 0604) was used the speed of the tearing 2 - initial speed was 1 $\mathrm{mm} / \mathrm{min}$ to the module $2 \%$, then the speed was increased to $100 \mathrm{~mm} / \mathrm{min}$ until rupture. For tensile tensile strength, elongation et break, tensile-Chor modulus and yield stress were measured and evaluated.

DMA measurements were performed on samples of size $50 \times 10 \mathrm{~mm}$ made from pre-molded panels on the device DMA DX04T fy RMI in laboratories FT UTB Zlin.

\section{Gas barrier properties}

The observed nanocomposite molded films with the thickness of about $50 \mu \mathrm{m}$ were used for the measurement of $\mathrm{N}_{2}, \mathrm{O}_{2}$ and $\mathrm{CO}_{2}$ permeability, the equipment based on ČSN 64 0115, method of a constant volume.

\section{RESULTS AND DISSCUSION}

Mechanical properties. Polymer/clay nanocomposites have been studied for longer period as materials possible used in packaging industry. Therefore, this work is particularly interested in the mechanical properties. Table 1 and 2 presents the mechanical properties of polymers with nanofillers and the inside surface of the polymeric matrix.

In the table 1 , it is possible to see the effect of fillers on tensile strength, tensile modulus and elongation. As it can be see, the values of net PP, PE and Surlyn are higher than the same materials enriched by fillers. Especially PP samples with fillers show significantly lower tensile strength. It can be assumed that the presence of filler in samples, compared to the net ones, has not a significant effect on tensile strength. However interesting is the fact that filled Surlyn had lower tensile strength, despite the fact that according to X-ray and TEM achieves the highest degree of exfoliation. Tensile modulus values were higher in samples filled with PE and Surlyn ${ }^{25,27-29}$.

TABLE 1. Tensile tests - filler within the polymer matrix

\begin{tabular}{lcccc}
\hline Composition & $\begin{array}{c}\text { Stress at break } \\
(\mathbf{M P a})\end{array}$ & $\begin{array}{c}\text { Elongation at break } \\
(\boldsymbol{\%})\end{array}$ & $\begin{array}{c}\text { Yield stress } \\
(\mathbf{M P a})\end{array}$ & $\begin{array}{c}\text { Tensile modulus } \\
(\mathbf{M P a})\end{array}$ \\
\hline PP/93A & 8,601 & 601,08 & 22,34 & 307,67 \\
PP/67 & 8,657 & 619,08 & 21,01 & 313,97 \\
PP & 28,592 & 948,48 & 20,32 & 320,57 \\
PE/10A & 13,323 & 862,04 & 9,76 & 142,37 \\
PE/30B & 13,261 & 833,74 & 10,08 & 145,74 \\
PE & 15,903 & 790,30 & 9,73 & 117,37 \\
EVA/93 & 20,580 & 1171,00 & 0,00 & 42,15 \\
EVA/67 & 20,071 & 1112,10 & 0,00 & 38,60 \\
EVA & 19,51 & 1173,40 & 0,00 & 26,92 \\
SRL/93 & 22,65 & 461,94 & 13,72 & 206,67 \\
SRL/67 & 23,14 & 449,78 & 13,36 & 206,97 \\
SRL & 30,45 & 555,94 & 12,75 & 167,85 \\
\hline
\end{tabular}

In the table 2, we can see that the filler material surface showed almost the same values as the pure material. The problem was that during tensile tests with the deposition of filler on the surface began to tear sooner than the blades. The surface layer tore already at $12 \%$ elongation in almost all cases. Changing the properties in the case of the filler on the surface of the polymer matrix may also be caused by disruption of the surface of the blades during the deposition of filler (solvent effect). 
TABLE 2. Tensile tests - filler on the surface of the polymer matrix

\begin{tabular}{lccc}
\hline Composition & $\begin{array}{c}\text { Stress at break } \\
(\mathbf{M P a})\end{array}$ & $\begin{array}{c}\text { Elongation at break } \\
\mathbf{( \% )}\end{array}$ & $\begin{array}{c}\text { Tensile modulus } \\
\mathbf{( M P a})\end{array}$ \\
\hline EVA/93 & 16,58 & 1189,80 & 40,07 \\
EVA/67 & 17,49 & 1254,30 & 34,26 \\
EVA & 19,51 & 1173,40 & 26,917 \\
SRL/93 & 26,25 & 736,10 & 197,69 \\
SRL/67 & 27,09 & 565,27 & 192,77 \\
SRL & 30,45 & 555,94 & 167,85 \\
\hline
\end{tabular}

Tensile modulus at EVA filler surface and Surlyn with the filler surface slightly improved. The same fact was also observed for the filler within the polymer matrix. As shown by mechanical testing - the filler achieves a high degree of exfoliation, there is no difference in the imposition of filler - in a polymer matrix or at the surface ${ }^{26,30-34}$.

DMA. In the table 3 the highest values of the dynamic modulus of elasticity are summarized, both the filled PP (PP / Dellite 67 and PP / Cloisite 93A). Conversely, all EVA samples have the lowest dynamic modulus ${ }^{31}$. In comparison with pure samples of all the filler the dynamic modulus increases.

TABLE 3. Comparison of dynamic modulus of samples

\begin{tabular}{lcc}
\hline Composition & $\begin{array}{c}\text { Module E (absolute) } \\
\text { (MPa) }\end{array}$ & $\begin{array}{c}\text { Loss angle } \\
\tan \boldsymbol{\delta}\end{array}$ \\
\hline PP/93A & 8,601 & 601,08 \\
PP/67 & 8,657 & 619,08 \\
PP & 28,592 & 948,48 \\
PE/10A & 13,323 & 862,04 \\
PE/30B & 13,261 & 833,74 \\
PE & 15,903 & 790,30 \\
EVA/93 & 20,580 & 1171,00 \\
EVA/67 & 20,071 & 1112,10 \\
EVA & 19,51 & 1173,40 \\
SRL/93 & 22,65 & 461,94 \\
SRL/67 & 23,14 & 449,78 \\
SRL & 30,45 & 555,94 \\
\hline
\end{tabular}

XRD. In order to discover the result of montmorillonite exfoliation in used matrices, XRD patterns have been taken. According to the recorded results it was possible to observe that no complete montmorillonite exfoliation has taken place. All plotted patterns show at least one peak which belongs to the MMT. To sum up, the complete exfoliation of nanofiller has not taken place in any clay mixture prepared. Moreover, the result is not influenced by MMT concentration and this holds true for all nanofillers observed.

As discussed below, despite the incomplete exfoliation shown by XRD measurement, a certain improvement of some qualities observed has taken place. The distribution of next types of used (nano)filler was evaluated by TEM and the good level of it was approved.

Best results in X-ray diffraction can be observed Surlyn, where curves of both filled materials are compared with pure sample and they are almost identical, with no peaks. It can be stated that only filled Surlyn probably occurred highest grade of exfoliation when comparing the prepared samples ${ }^{35,36}$. 


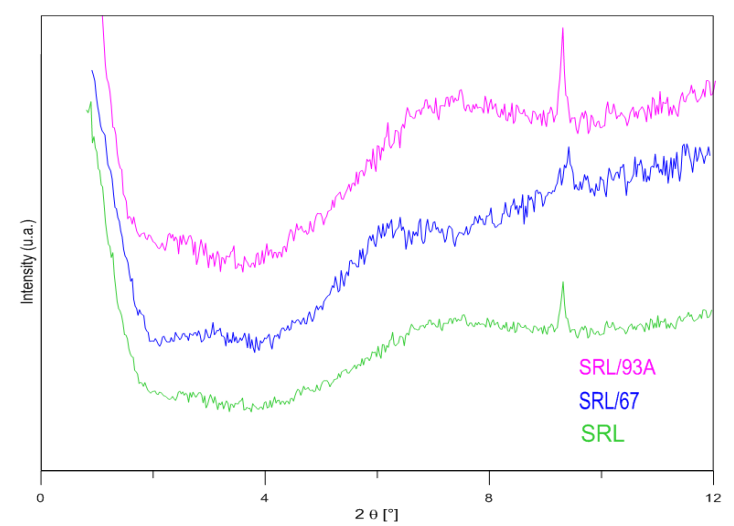

FIG. 2. XRD Surlyn nanofillers, pure Surlyn, surlyn + MMT 93A 5\% and surlyn + MMT $675 \%$

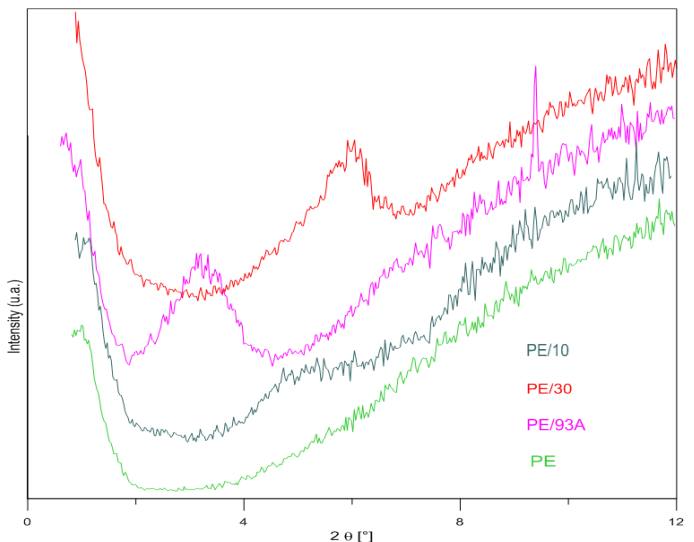

FIG. 3. XRD PE nanofillers, PE +MMT 93A, 30, 10(5\% wt filling)

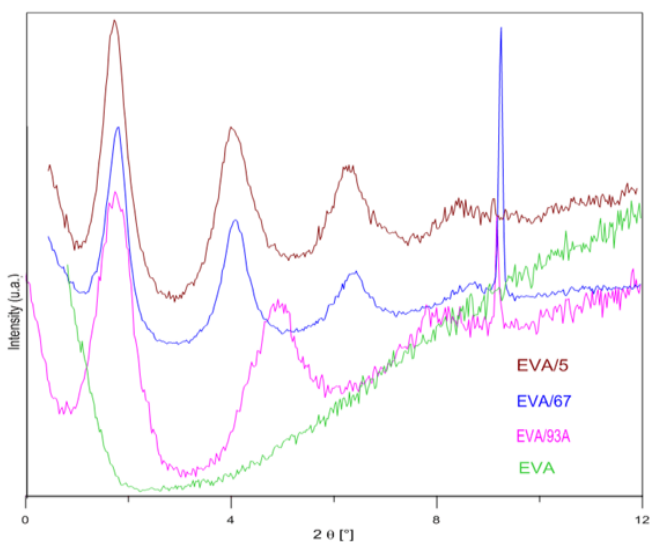

FIG. 4. XRD EVA nanofillers, EVA +MMT 93A, 67,5 (5\% wt filling)

In the figure 3 and 4 the curves PE samples with Cloisite 93A and 30 show peaks indicating a low degree of exfoliation. Only PE with Cloisite 10A shows in comparison with pure PE desired degree of exfoliation of the filler in the polymer matrix.

EVA enriched of nanofiller exhibits peaks in all three samples with nanofillers. In comparison with a pure sample shows that the desired degree of exfoliation of the filler in the matrix did not occur, which was confirmed by TEM.

TEM. The exfoliation was very successful for Surlyn as it comes from results of TEM analysis. In Figure 5 it can be seen comparison of the distribution of nanofiller in a matrix of EVA and Surlyn. Distribution in both cases is about the same, but images suggest that in the case of EVA matrix the exfoliation is worse ${ }^{32,34-36}$.

A) SURLYN+MMT 93A 5\%

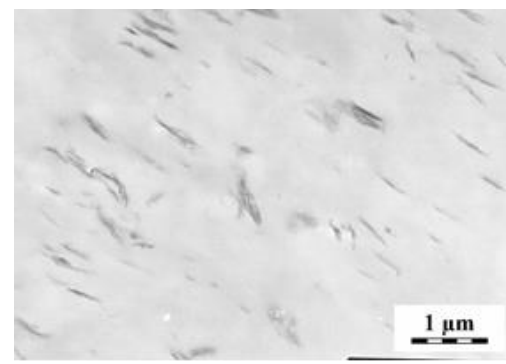

FIG. 5. TEM Pictures of Surlyn a EVA Nanocomposites
B) EVA+ MMT 93A 5\%

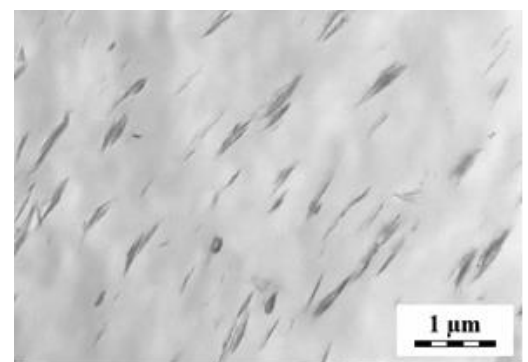



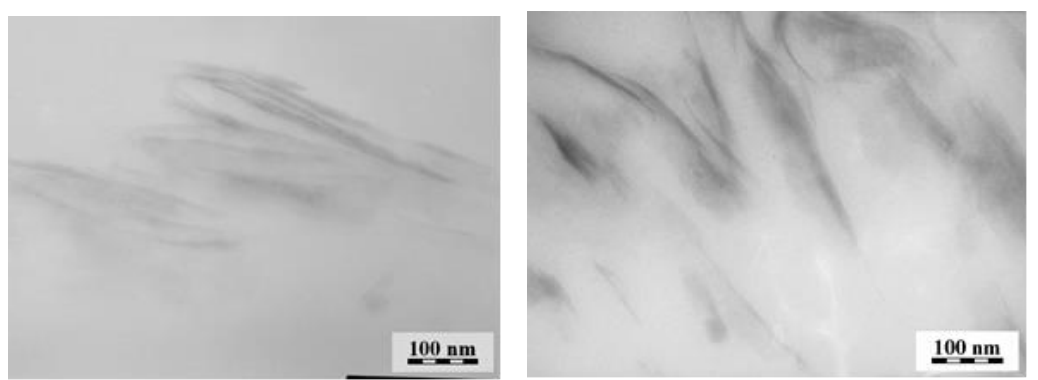

FIG. 6. TEM - The same picture pictures of Surlyn a EVA Nanocomposites in higher resolution

Permeability. As mentioned above, PE, PP and EVA copolymer are polymers used in packing industry. Therefore, our study also covers the values of permeability for $\mathrm{O}_{2}$ and $\mathrm{CO}_{2}$, which are mediums that should be prevented from penetrating through film, e.g. in case of food wrapping.

In this instance, films extruded on a flat extrusive dye were used as samples for the purpose of measurement.

The evaluation of the $\mathrm{O}_{2}$ permeability (see Fig 5) shows for PE, PP and copolymer EVA matrices. The nanofiller Cloisite $30 \mathrm{~B}$ is totally unsuitable, for all used polymers, similar result was achieved for microprecipittated $\mathrm{CaHCO}_{3}$, nanosilica and Halloysite tubes. Only for nanofillers N 5 and 3000 and Cloisite 93A the result of permeability observation was better in the comparison of unfilled matrices. In Fig. 3 the measurement of $\mathrm{CO}_{2}$ permeability is presented. The result is the similar like for $\mathrm{O}_{2}$ observation. Also for $\mathrm{CO}_{2}$ Cloisite $30 \mathrm{~B}$ confirmed the position of bad filler for these matrices. Unfortunately, in case of EVA no nanofiller showed the significant lowering of $\mathrm{CO}_{2}$ permeability. The best lowering for gases permeability was achieved for the combination of $\mathrm{PE}$ and Cloisite $93 \mathrm{~A}$.

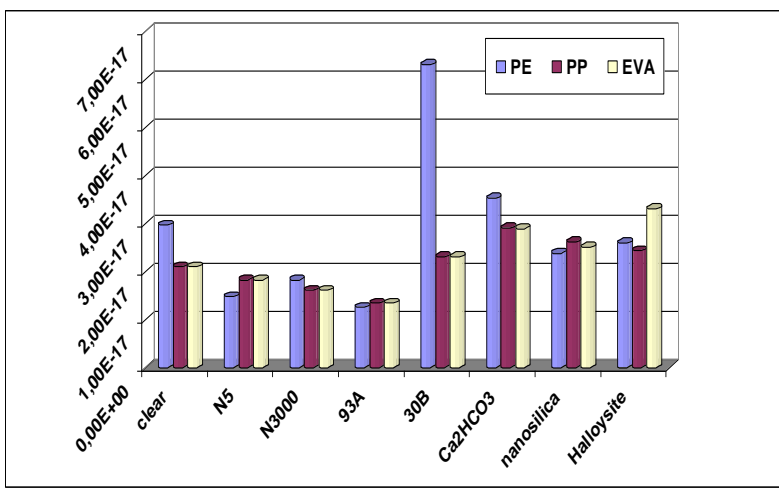

FIG. 5. Graph of $\mathrm{O}_{2}$ permeability (5\% wt filling)

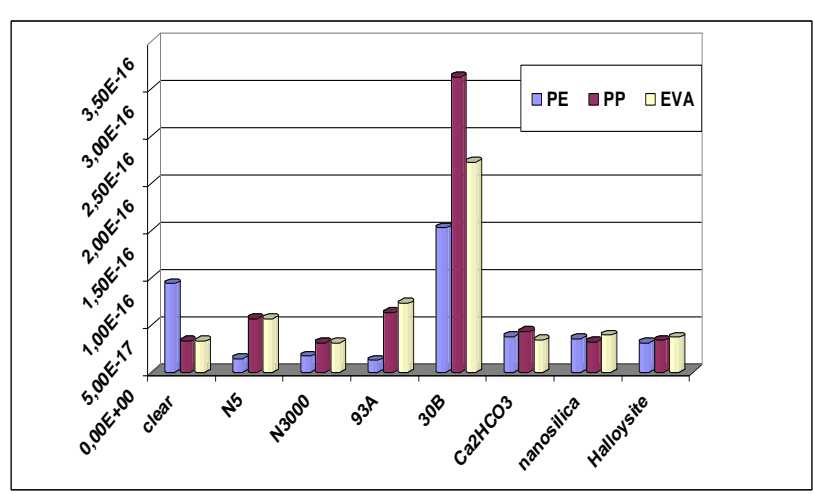

FIG. 6. Graph of $\mathrm{CO}_{2}$ permeability (5\% wt filling)

In the table 3 and 4 we can see that in the filler Cloisite 93A (compared - if the filler inside and on the surface) at the measured samples transmittance changed only slightly, while at the longer filler 67 applied on the surface decreased permeation rate by almost half in both studied materials.

Table 3: The permeation coefficient for N2 permeability - samples with filler surface

\begin{tabular}{lcc}
\hline Composition & $\begin{array}{r}\text { Thickness } \\
(\mathbf{m m})\end{array}$ & $\begin{array}{c}\text { Permeation coefficien } \\
(\mathbf{m o l} / \mathbf{m} . \mathbf{s . P a})\end{array}$ \\
\hline EVA/93A & 0,042 & $5,9811 \cdot 10^{-15}$ \\
EVA/67 & 0,042 & $6,8093 \cdot 10^{-15}$ \\
EVA & 0,083 & $12,04 \cdot 10^{-15}$ \\
SRL/93A & 0,013 & $2,2365 \cdot 10^{-15}$ \\
SRL/67 & 0,013 & $1,9238 \cdot 10^{-15}$ \\
SRL & 0,013 & $1,9534 \cdot 10^{-15}$ \\
\hline
\end{tabular}


Table 4. The permeation coefficient of $\mathrm{N}_{2}$ permeability - samples with filler inside

\begin{tabular}{lcc}
\hline Composition & $\begin{array}{c}\text { Thickness } \\
(\mathbf{m m})\end{array}$ & $\begin{array}{c}\text { Permeation coefficient } \\
(\mathbf{m o l} / \mathbf{m . s . P a}\end{array}$ \\
\hline $\mathrm{PP} / 93 \mathrm{~A}$ & 0,0737 & $9,6384 \cdot 10^{-15}$ \\
$\mathrm{PP} / 67$ & 0,0527 & $6,7048 \cdot 10^{-15}$ \\
$\mathrm{PP}$ & 0,0343 & $4,7423 \cdot 10^{-15}$ \\
$\mathrm{PE} / 93 \mathrm{~A}$ & 0,0507 & $6,6115 \cdot 10^{-15}$ \\
$\mathrm{PE}$ & 0,0250 & $3,3931 \cdot 10^{-15}$ \\
EVA/93A & 0,0300 & $5,1537 \cdot 10^{-15}$ \\
EVA/67 & 0,0653 & $11,2880 \cdot 10^{-15}$ \\
EVA/5 & 0,0837 & $10,4240 \cdot 10^{-15}$ \\
EVA & 0,0830 & $12,0400 \cdot 10^{-15}$ \\
SRL/93A & 0,0147 & $2,1852 \cdot 10^{-15}$ \\
SRL/67 & 0,0423 & $5,4436 \cdot 10^{-15}$ \\
SRL & 0,0133 & $1,9534 \cdot 10^{-15}$ \\
\hline
\end{tabular}

It can be concluded that the longer the filler 67 applied on the surface of the matrix may better influence the permeability of the material-gas. This may be due to a better distribution and dispersion of filler, or better exfoliation MMT coating the surface of the matrix (solvent effect).

Surlyn with the longer 67 within the polymer matrix has a much higher throughput, truth-alike would be better used for other Surlyn filler of this type.

\section{CONCLUSION}

PE, PP and EVA copolymer matrices with seven types of commercial (nano)fillers with the different structures, particles type and size were prepared and observed. Because of using of mentioned materials for food packaging, the morphology of prepared samples, mechanical properties and barrier properties were checked. Although the TEM and XRD measurement did not show the full exfoliation of clay nanofillers in the polymer matrix, the very good result in case of mechanical and barrier properties were found, especially for PE matrix. Cloisite 30B was found not to suitable for these types of polymers. Higher concentration (5\%wt) brought more significant lowering of gases permeability.

Comparison of mechanical properties and exfoliation of the nanofiller in the polymer matrix was observed. Platelets of montmorillonite overlapped and may cause deterioration of the desired properties. The goal of the production of polymer nanocomposites is to achieve the full exfoliation. Important is the observation that nanofillers within the polymer matrix or on the surface of the polymer matrix mechanics affect polymer properties. We can say that good exfoliation of fillers can improve mechanical properties of nanocomposites. Nevertheless, the degree of exfoliation and orientation of the platelets is the most critical parameter.

\section{ACKNOWLEGEMENT:}

This article (specify by the fact) was written with support of Operational Program Research and Development for Innovations co-funded by the European Regional Development Fund (ERDF) and national budget of Czech Republic, within the framework of project Centre of Polymer Systems (reg. number: CZ.1.05/2.1.00/03.0111), by the project TA03010799, FR TI 4/623 and IGA/FT/2014/014 TBU in Zlin. Some of presented data were already published.

\section{REFERENCES:}


[2] J. K. Mishra, K. J. Hwang, CS. Ha, Polymer, 46 (6): 1995 (2005).

[3] T. Gokkurt, A. Durmus, V. Sariboga, M. A. F. Oksuzomer, J. of App. Pol. Sci., 129 (5): 2490 (2013).

[4] Y.Turhan, Z. G. Alp, M. Alkan, M. Dogan, Microporous and Mesoporous Materials, 174 : 144 (2013).

[5] I. S. Suh, S. H. Ryu, J. H. Bae, et al., J. Appl. Pol. Sci, 94 (3): 1057 (2004).

[6] T. M. Wu, J. Y. Wu, J. Macromol. Sci-Phys: B41 (1): 17(2002).

[7] P. Santamaria, J. I. Eguiazabal, 24 (3): 300 (2013).

[8] C. M. Koo, M. J. Kim, M. H. Choi, et al, J. Appl. Pol. Sci, 88 (6): 1526 (2003).

[9] Y. Wang, F. B. Chen, Y. C. Li, et al., Composites Part B-Engineeering , 35 (2): 111 (2004).

[10] S. Peeterbroeck, M. Alexandre, R. Jerome, et al., Pol. Degr. Stab., 90 (2): 288 (2005).

[11] Y. Tang, Y. Hu, J. Z. Wang, et al, J. Appl. Pol. Sci, 91 (4): 2416 (2004).

[12] C. H. Jeon, S. H. Ryu, Y. W. Chang, Pol. Inter., 52 (1): 153 (2003).

[13] R. S. N. Amiri, T. Tirri, C. E. Wilen, J. of App. Pol. Sci, 129 (4): 1678 (2013).

[14] G.Zehetmeyer, J. M. Scheibel, R. M. D. Soares, D. E. Weibel, M. A.S. Oviedo, R. V. B. Oliveira, Pol. Bulletin, 70 (8): 2181 (2013).

[15] Y. Tang, Y. A. Hu, S. F. Wang, et al.,

[16] Y. Zhong, Z. Y. Zhu, S. Q. Wang, Polymer, 46 (9): 3006 (2005).

[17] Gaidukov, S.; Maksimov, R. D.; Cabulis, U.; et al., Mechanics of Composite Materials, 49 (4), 333-344 (2013)

[18] V. Nigam, D. K. Setua, G. N. Mathur, et al., J. Appl. Pol. Sci., 93 (5): 2201 (2004).

[19] H. Zheng, Y.,ZhangZ.L. Peng, et al., Pol. Test., 23 (2): 217 (2004).

[20] N. N. Bhiwankar, R. A. Weiss, Polymer, 46 (18): 7246 (2005).

[21] H. Fernanda, Quinzani, L. M.; Failla, Marcelo D., J. of Thermoplastics Composite Materials, 27 (1), $106-125$ (2014 )

[22] S. S. Lee, J. Kim, J. Pol. Sci. Part B-Pol. Phys., 42 (12): 2367 (2004).

[24] Bergaya F, Lagaly G., Appl. Clay Sci., 19 (1-6): 1-3 Sp. Iss. SI (2001).

[25] Q. P. Ran, H. Y. Hua and Y. Tian, et al., Polymers \& Polymer Composites, 14 ( 3) 301-306 (2006)

[27] M. H. Abdolrasouli, E. Behzadfar and H. Nazockdast, et al., Journal of Applied Polymer, 125 (1) E435-E444 (2012)

[26] A. Sharif-Pakdaman, J. Morshedian and Y. Jahani, Journal of Applied Polymer, 125 (1), E305-E313 (2012)

[28] H. K. F. Cheng, N. G. Sahoo and X Lu; et al., , Journal of Thermal Analysis and Calorimetry, 109 ( 1) 17-25 (2012)

[29] L. Xie, L. Xia-Yan and Z-J. Han, et al., Polymer Plastic Technology and Engineering,_51 (12), 1251-1257 (2012)

[30] B. Akbari and R. Bagheri, Journal of Nanocomposites, 810623 (2012)

[31] V. Goodarzi, S. H. Jafari, and H. A. Khonakdar, et al., Journal of Polymer Research,_18 (6), 1829-1839 (2011)

[32] F. - Ch. Chiu, H. - Z. Yen and Ch. - E. Lee, Polymer Testing, 29 (3), 397-406 (2010)

[33] Y. Zhong, D. Janes and Y. Zheng, et al, Polymer Engineering and Science,47 (7) , 1101-1107 (2007 
[34] H. M. Yang, O. Zheng and M. Du, Chemical Research in Chinese Universites, 22 (5), 651-657 (2006)

[35] H. M. Yang, Y. H. Song and B. Xu, et al., Chemical Research in Chinese Universites 22 (3), 383-387 (2006)

[36] A. Szep, A. Szabo and N. Toth, et al._Polymer Degradation and Stability, 91 (3), 593-599 (2006) 